\title{
Nanoscale
}

Cite this: Nanoscale, 2013, 5, 4986

\section{Effective photocatalysis of functional nanocomposites based on carbon and $\mathrm{TiO}_{2}$ nanoparticlest}

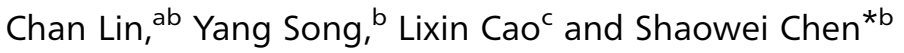 \\ A unique nanocomposite $\mathrm{C}-\mathrm{TiO}_{2}$ was prepared by the growth of $\mathrm{TiO}_{2}$ on carbon nanoparticles using a \\ simple hydrothermal procedure. Transmission electron microscopic (TEM) measurements showed that \\ the nanocomposites exhibited an average core diameter of approximately $5 \mathrm{~nm}$ with a rather well- \\ defined lattice space $(0.4 \mathrm{~nm})$ that was somewhat larger than that $(0.38 \mathrm{~nm})$ of the $(100)$ crystalline \\ planes of anatase $\mathrm{TiO}_{2}$. This lattice expansion was accounted for by the formation of surface defect \\ dipoles of the nanosized $\mathrm{TiO}_{2}$ particles. X-ray photoelectron spectroscopic (XPS) measurements \\ suggested that partial charge transfer occurred from carbon nanoparticles to $\mathrm{TiO}_{2}$ by the interfacial Ti- \\ $\mathrm{O}-\mathrm{C}$ linkages, which led to effective diminishment of the $\mathrm{C}-\mathrm{TiO}_{2}$ photoluminescence as compared to \\ that of pure $\mathrm{TiO}_{2}$ or carbon nanoparticles, suggesting intimate electronic interactions between the \\ carbon and $\mathrm{TiO}_{2}$ components in the nanocomposites. Such unique characteristics were then exploited \\ for the effective photocatalytic degradation of organic pollutants, as exemplified by methylene blue, by \\ $\mathrm{C}-\mathrm{TiO}_{2}$ under UV photoirradiation. Experimental measurements showed that the photocatalytic activity \\ of $\mathrm{C}-\mathrm{TiO}_{2}$ nanocomposites was about twice that of $\mathrm{TiO}_{2}$ alone, whereas little activity was observed with \\ carbon nanoparticles. This was attributed to the electron-accepting sites on the carbon nanoparticles \\ that facilitated interfacial charge separation.
}

Received 27th February 2013

Accepted 3rd April 2013

DOI: $10.1039 / c 3 n r 01033 c$

www.rsc.org/nanoscale

activated carbon. ${ }^{25-27}$ For instance, Chu et al. ${ }^{17}$ prepared carbondoped nanostructured $\mathrm{TiO}_{2}$ films (the average size of the nanoparticles was about $40 \mathrm{~nm}$ ) with oxalic acid and tetrabutylammonium bromide as the carbon sources and the carbondoped into the lattice sites of $\mathrm{TiO}_{2}$, leading to apparent narrowing of the $\mathrm{TiO}_{2}$ bandgap and hence improved efficiency of photoenergy utilization. In another study, ${ }^{20}$ carbon-doped $\mathrm{TiO}_{2}$ nanotubes, nanowires and nanorods were prepared by utilizing the nanoconfinement of hollow titanate nanotubes. The procedure entailed two steps, adsorption of ethanol onto the inner walls of the nanotubes and thermal treatment of the complex in an inert nitrogen atmosphere. The resulting catalysts exhibited enhanced photocatalytic activity in the degradation of toluene in the gas phase under both visible and simulated solar light irradiation, as compared to that of commercial Degussa P25. Carbon dopants have also been incorporated into $\mathrm{TiO}_{2}$ micro/nanospheres and nanotubes by chemical vapor deposition in an inert atmosphere, and the resulting $\mathrm{TiO}_{2}$ exhibited much higher photocurrents than commercial P25. ${ }^{28,29}$ In these studies, the key motivation is to engineer the $\mathrm{TiO}_{2}$ bandgap by carbon dopants so that the efficiency of light absorption and utilization can be improved. However, the synthetic procedure typically requires rather harsh experimental conditions and/or sophisticated instrumentation, and the lack of structural stability of the dopants might compromise the durability of the photocatalysts.

Another effective strategy is to prepare carbon and $\mathrm{TiO}_{2}$ nanocomposites. For instance, carbon-coated anatase $\mathrm{TiO}_{2}$

${ }^{a}$ College of Chemistry and Chemical Engineering, Ocean University of China, Qingdao, Shandong 266100, China

${ }^{b}$ Department of Chemistry and Biochemistry, University of California, 1156 High Street, Santa Cruz, California 95064, USA. E-mail: shaowei@ucsc.edu

'Institute of Materials Science and Engineering, Ocean University of China, Qingdao, Shandong 266100, China

† Electronic supplementary information (ESI) available: XRD patterns of $\mathrm{TiO}_{2}$ and C- $-\mathrm{TiO}_{2}$ nanoparticles. See DOI: 10.1039/c3nr01033c 
catalysts ( $>20 \mathrm{~nm}$ in diameter) have been prepared by heating a mixture of poly(vinyl alcohol) and commercial $\mathrm{TiO}_{2}$ at elevated temperatures (700-900 ${ }^{\circ} \mathrm{C}$ ), which exhibited markedly enhanced photocatalytic activity in the degradation of methylene blue, as compared to that of the original commercial $\mathrm{TiO}_{2} \cdot{ }^{30}$ This was ascribed to the improved crystalline structure of the anatase $\mathrm{TiO}_{2}$ after the heating treatments as well as the suppression of phase transformation from anatase to rutile by the carbon coating layer. In another study, ${ }^{27}$ effective photocatalysts were prepared by homogeneous dispersion of $\mathrm{TiO}_{2}$ on activated carbon cloths by a process of dip-coating and subsequent annealing in a nitrogen atmosphere, and the photocatalytic activity was assessed quantitatively by the photodegradation of methylene blue under UV irradiation. Yet, in these early studies, the $\mathrm{TiO}_{2}$ nanoparticles are typically rather large (diameter of the order of tens of $\mathrm{nm}$ ), and whereas the photocatalytic activity of the nanocomposites might be apparently improved, the impacts of the electronic interactions between carbon and $\mathrm{TiO}_{2}$ are mostly ignored.

In the present study, we report the facile synthesis of a functional nanocomposite based on carbon and $\mathrm{TiO}_{2}$ nanoparticles. The carbon nanoparticles were prepared by refluxing the combustion soot of natural gas in nitric acid, and then mixed with titanium(Iv) $n$-butoxide to form $\mathrm{C}-\mathrm{TiO}_{2}$ composite nanoparticles by using a simple hydrothermal process. XPS and photoluminescence studies of $\mathrm{C}-\mathrm{TiO}_{2}$ suggested that there were effective electronic interactions between the carbon and $\mathrm{TiO}_{2}$ components in the nanocomposites, as compared to pure $\mathrm{TiO}_{2}$ nanoparticles. This unique characteristic led to a marked improvement of the photocatalytic activity of the resulting $\mathrm{C}$ $\mathrm{TiO}_{2}$ nanocomposites in the photodegradation of methylene blue, which was about twice that of the $\mathrm{TiO}_{2}$ nanoparticles alone.

\section{Experimental section}

\section{Chemicals}

Nitric acid $\left(\mathrm{HNO}_{3}, 69.8 \%\right.$, Fisher), sodium carbonate anhydrous ( $\mathrm{Na}_{2} \mathrm{CO}_{3}, 99 \%$, Fisher Scientific), 3-chloroaniline (99\%, ACROS), titanium(Iv) $n$-butoxide (99\%, ACROS), oleic acid (Fisher Scientific), and methylene blue (ACROS) were used as received without further treatment. Water was supplied by a Barnstead Nanopure Water System (18.3 $\mathrm{M} \Omega \mathrm{cm})$.

\section{Synthesis of carbon nanoparticles (CNP)}

The preparation of carbon nanoparticles has been reported in our previous studies. ${ }^{31,32}$ In brief, carbon soot was collected from the inside wall of a glass beaker by placing the beaker upside-down above the flame of a natural gas burner. Then $100 \mathrm{mg}$ of soot was refluxed in $10 \mathrm{~mL}$ of $\mathrm{HNO}_{3}(5 \mathrm{M})$ for $12 \mathrm{~h}$. After cooling down to room temperature, the brownish yellow supernatant was filtered and then neutralized by $\mathrm{Na}_{2} \mathrm{CO}_{3}$. Finally, the sample was dialyzed against Nanopure water through a dialysis membrane for 3 days, affording purified carbon nanoparticles (CNP). Transmission electron microscopic (TEM) measurements showed that the nanoparticles exhibited a mixture of amorphous and graphitic structures and an average core diameter of $4.8 \pm 0.6 \mathrm{~nm} .^{31,32}$

\section{Synthesis of $\mathrm{TiO}_{2}$ nanoparticles}

$\mathrm{TiO}_{2}$ nanoparticles were prepared by a hydrothermal method. ${ }^{33}$ Briefly, $0.1 \mathrm{~mL}$ of 3-chloroaniline was added into $15 \mathrm{~mL}$ of Nanopure water, and then transferred to a Teflon-lined stainless-steel autoclave. Subsequently, $0.17 \mathrm{~g}$ of titanium(Iv) $n$-butoxide and $1.0 \mathrm{~mL}$ of oleic acid were dissolved in $10 \mathrm{~mL}$ of toluene and then transferred to the autoclave. The mixed solution was then subject to hydrothermal reactions at $180{ }^{\circ} \mathrm{C}$ for $12 \mathrm{~h}$. The white precipitates were collected and extensively rinsed with methanol.

\section{Synthesis of carbon hybridized $\mathrm{TiO}_{2}$ nanoparticles $\left(\mathrm{C}-\mathrm{TiO}_{2}\right)$}

The preparation and processing of carbon hybridized $\mathrm{TiO}_{2}$ was the same as that of $\mathrm{TiO}_{2}$ described above. The only difference was to add $15 \mathrm{mg}$ of carbon nanoparticles to the water phase at a concentration of $1 \mathrm{mg} \mathrm{mL} \mathrm{mL}^{-1}$ prior to the hydrothermal procedure. The resulting $\mathrm{C}-\mathrm{TiO}_{2}$ nanocomposite contained about $27 \mathrm{wt} \%$ of carbon.

\section{Characterization}

Transmission electron microscopy (TEM) studies were carried out with a JOEP JEM-2010 TEM microscope operated at $200 \mathrm{kV}$. The samples were prepared by suspending the powder sample in toluene and dropcasting onto a $\mathrm{Cu}$ grid. UV-vis absorption spectra of the samples were measured with an ATI Unicam UV4 spectrometer by using a $1 \mathrm{~cm}$ quartz cuvette with a resolution of $2 \mathrm{~nm}$. Fluorescence spectra were acquired with a PTI photoluminescence spectrometer. X-ray photoelectron spectra (XPS) were recorded with a PHI 5400 XPS instrument equipped with an $\mathrm{Al} \mathrm{K} \alpha$ source operated at $350 \mathrm{~W}$ and at $10^{-9}$ Torr. The spectra were charge-referenced to the Au $4 \mathrm{f}_{7 / 2}$ peak $(83.8 \mathrm{eV})$ of sputtered gold.

\section{Photocatalysis}

Methylene blue at the concentration of $20 \mathrm{mg} \mathrm{L}^{-1}$ was used as the testing solution, and a UV lamp (365 nm, $6 \mathrm{~W}$ ) was employed as the light source. In a typical experiment, $2 \mathrm{~mL}$ of the methylene blue solution was added into a quartz cuvette and $1 \mathrm{mg}$ of photocatalysts was added into the solution and mixed under magnetic stirring for at least $2 \mathrm{~h}$ in the dark to establish an adsorption/desorption equilibrium, prior to exposure to the light source. In photocatalytic assessments, the distance between the light source and the cuvette was $c a .10 \mathrm{~cm}$. The solution was under magnetic stirring during the entire experimental procedure. The photocatalytic activities were quantified by collecting the UV-vis absorption spectra of the solution at different reaction intervals.

\section{Results and discussion}

Fig. 1 depicts two representative TEM micrographs of (A and $\mathrm{B}$ ) $\mathrm{TiO}_{2}$ and (C and D) $\mathrm{C}-\mathrm{TiO}_{2}$ nanoparticles. Despite rather 

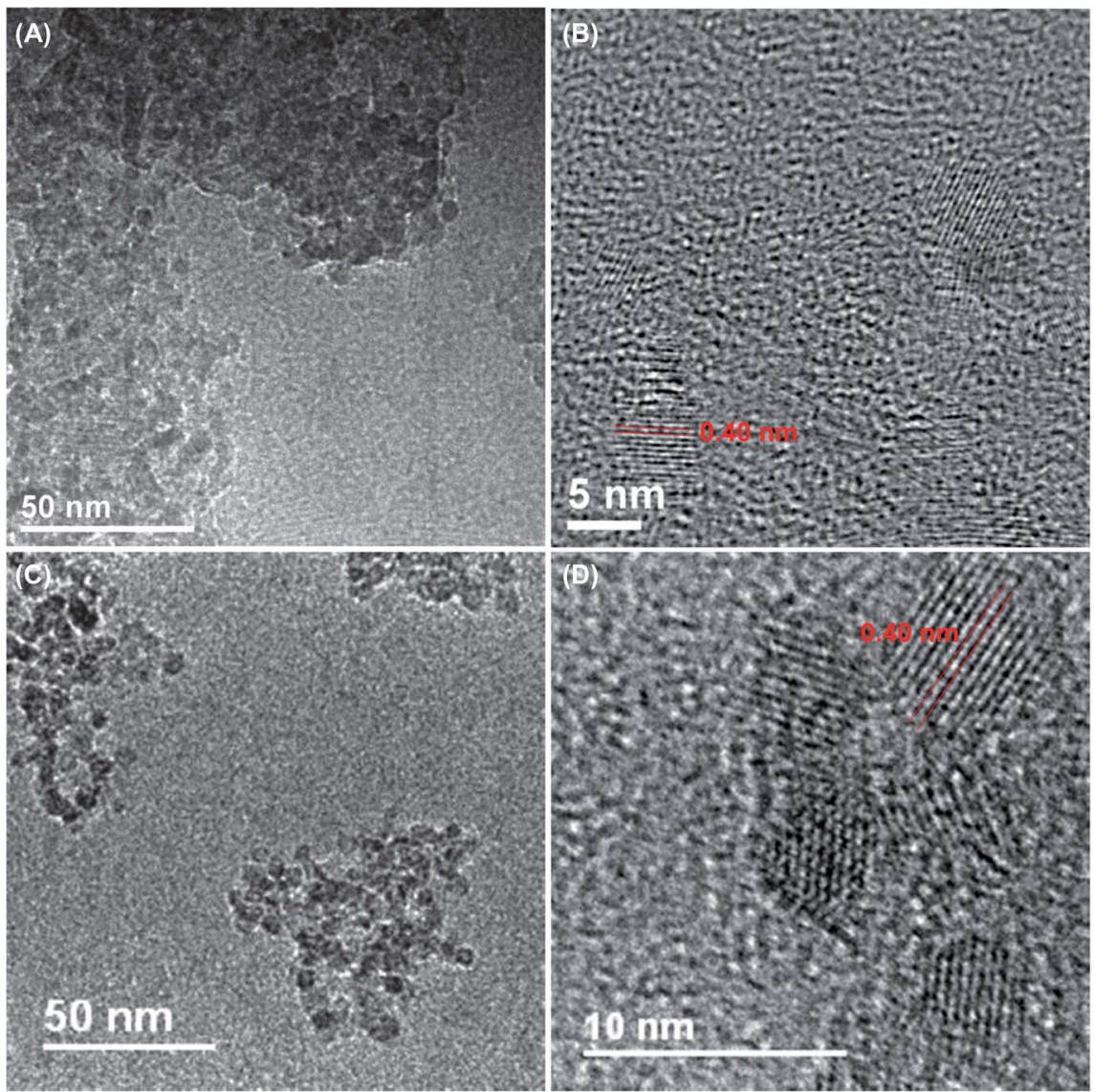

Fig. 1 Representative TEM micrographs of $(A$ and $B) \mathrm{TiO}_{2}$ and $(\mathrm{C}$ and $\mathrm{D}) \mathrm{C}-\mathrm{TiO}_{2}$ nanoparticles. Red lines highlight the lattice fringes of $\mathrm{TiO}_{2}$.

extensive agglomeration in both samples (panels A and C), individual particles remained resolvable with a largely spherical shape and an average diameter of $5.20 \mathrm{~nm}$ and $5.05 \mathrm{~nm}$ for the $\mathrm{TiO}_{2}$ and $\mathrm{C}-\mathrm{TiO}_{2}$ nanoparticles, respectively. In addition, highresolution TEM measurements exhibited well-defined lattice fringes in both $\mathrm{TiO}_{2}$ and $\mathrm{C}-\mathrm{TiO}_{2}$ nanoparticles, where the lattice spacing was estimated to be $c a .0 .40 \mathrm{~nm}$ (red lines). This is somewhat larger than the $d$-spacing $(0.38 \mathrm{~nm})$ of the (100) diffracting planes of bulk anatase $\mathrm{TiO}_{2}{ }^{34}$ In a previous study it was found that $\mathrm{TiO}_{2}$ exhibited an apparent linear lattice expansion with a diminishment of the grain size to the nanometer regime $(<50 \mathrm{~nm})$, as a result of the formation of surface defect dipoles, in contrast with metal nanoparticles that typically exhibited positive surface pressure and hence lattice contraction instead with shrinking physical dimensions. ${ }^{35}$ In the present study, the $\mathrm{TiO}_{2}$ nanoparticles were very small, only about $5 \mathrm{~nm}$ in diameter. Because of low coordination of the surface sites, bonding interactions with reactive molecules $\left(\right.$ e.g., $\left.\mathrm{H}_{2} \mathrm{O}\right)$ likely occurred, leading to the generation of surface defect dipoles and lattice expansion, as observed above. Nevertheless, one can see that in both samples the $\mathrm{TiO}_{2}$ nanoparticles were of rather pure crystalline phase and rich in high-energy $\{100\}$ facets, consistent with X-ray diffraction studies (Fig. S1†). This may be advantageous to their photocatalytic performance in the degradation of organic pollutants, as detailed below. ${ }^{34}$
In the above TEM study, it was difficult to resolve the carbon components in $\mathrm{C}-\mathrm{TiO}_{2}$ probably because of the low contrast and poor crystallinity as compared to $\mathrm{TiO}_{2}{ }^{32}$ Yet the electronic interactions between the carbon and $\mathrm{TiO}_{2}$ components in the $\mathrm{C}-\mathrm{TiO}_{2}$ hybrids were readily revealed by XPS measurements. Fig. 2(A) depicts the full survey spectra of the $\mathrm{TiO}_{2}$ and $\mathrm{C}-\mathrm{TiO}_{2}$ nanoparticles. One can see that in both samples the elements of $\mathrm{C}, \mathrm{Ti}$, and $\mathrm{O}$ can be clearly identified, with the binding energies of C1s, Ti2p and O1s electrons at approximately $286.6 \mathrm{eV}$, $459.4 \mathrm{eV}$ and $530.7 \mathrm{eV}$, respectively (the carbon signals in $\mathrm{TiO}_{2}$ were likely from the organic precursors used to prepare the nanoparticles, whereas in $\mathrm{C}-\mathrm{TiO}_{2}$, there were additional contributions from the carbon nanoparticles). However, highresolution scans showed that the exact binding energies of these electrons were slightly different, as revealed in panels (B) to (D). In panel (B), the Ti2 $\mathrm{p}_{1 / 2}$ and $2 \mathrm{p}_{3 / 2}$ electrons can be identified at $465.1 \mathrm{eV}$ and $459.4 \mathrm{eV}$ for the $\mathrm{TiO}_{2}$ nanoparticles (bottom curves), and slightly lower for $\mathrm{C}-\mathrm{TiO}_{2}$ at $465.0 \mathrm{eV}$ and $459.2 \mathrm{eV}$ (upper curves), suggesting a partial charge transfer from functional moieties on the carbon nanoparticle surface to the Ti(Iv) centers in the oxide nanoparticles. Nevertheless, these binding energies (and their corresponding spin-orbital splitting) are highly comparable to those reported in the literature for $\mathrm{TiO}_{2}$. For instance, in a previous study, for anatase $\mathrm{TiO}_{2}$ grown on multiwalled carbon nanotubes (MWCNT) the binding 


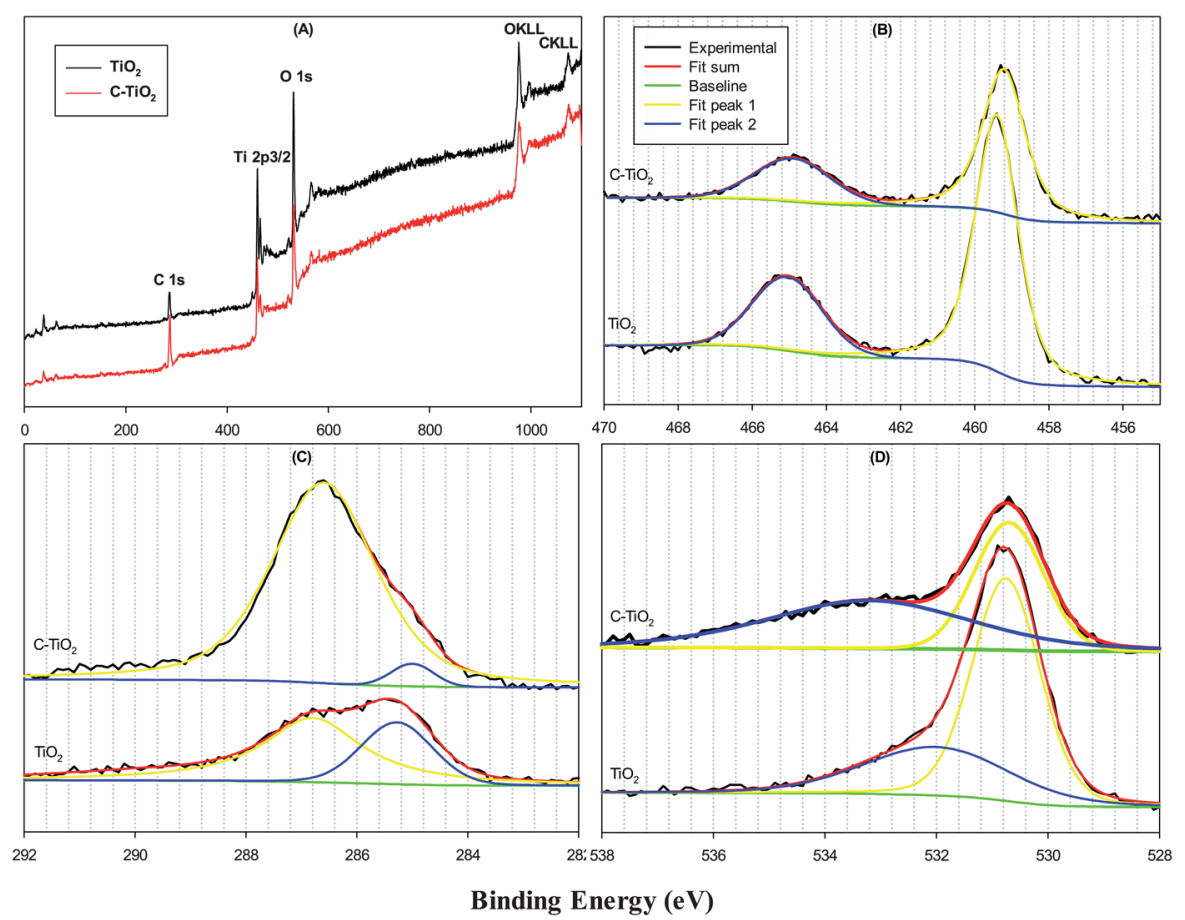

Fig. 2 (A) XPS survey spectra of $\mathrm{TiO}_{2}$ and $\mathrm{C}_{-} \mathrm{TiO}_{2}$ nanoparticles, and high-resolution scans of the binding energies of (B) $\mathrm{Ti2} p,(\mathrm{C}) \mathrm{C} 1 \mathrm{~s}$ and (D) O1s electrons in $\mathrm{TiO}_{2}$ (bottom curves) and $\mathrm{C}-\mathrm{TiO}_{2}$ (top curves) nanoparticles.

energies for Ti2p electrons were found at $464.9 \mathrm{eV}$ and $458.8 \mathrm{eV},{ }^{36}$ whereas for bulk anatase $\mathrm{TiO}_{2}$ at $464.5 \mathrm{eV}$ and $458.8 \mathrm{eV}$, respectively. ${ }^{37}$

Similar behaviors were observed with the binding energies of the C1s electrons. From panel (C), one can see that for $\mathrm{TiO}_{2}$ nanoparticles (bottom curves), there are two major peaks centered at $285.4 \mathrm{eV}$ and $286.8 \mathrm{eV}$, which may be assigned to the 1s electrons of $\mathrm{sp}^{2}$ hybridized carbon $(\mathrm{C}=\mathrm{C}$, for instance, from the aniline precursors used in $\mathrm{TiO}_{2}$ nanoparticle synthesis ${ }^{38}$ and to the formation of $\mathrm{Ti}-\mathrm{O}-\mathrm{C}$ carbonate species, ${ }^{36,39,40}$ respectively. For the $\mathrm{C}-\mathrm{TiO}_{2}$ nanoparticles (top curves), these two peaks red-shifted slightly to $285.0 \mathrm{eV}$ and $286.7 \mathrm{eV}$. The significantly greater intensity of the higher energy peak can be ascribed to the presence of carbon nanoparticles where the surface was decorated with various oxygenated functional species and they served as the anchoring sites for $\mathrm{TiO}_{2}$ nanoparticle growth. ${ }^{31,32}$ Furthermore, a small broad peak can be seen at around $290 \mathrm{eV}$, which may be assigned to the carboxylate C1s electrons on the carbon nanoparticle surface. ${ }^{31,32,36}$

For the O1s electrons, one can see from panel (D) that both $\mathrm{TiO}_{2}$ and $\mathrm{C}-\mathrm{TiO}_{2}$ nanoparticles exhibited an asymmetric peak within the range of $528 \mathrm{eV}$ to $538 \mathrm{eV}$, which might be deconvoluted into two major subpeaks. The lower energy peak was located at $530.8 \mathrm{eV}$ for $\mathrm{TiO}_{2}$ and $530.7 \mathrm{eV}$ for $\mathrm{C}-\mathrm{TiO}_{2}$ nanoparticles, which was assigned to oxygen bonded to $\mathrm{Ti}^{41-45}$ The binding energy of the Ti2p electrons was also somewhat lower with $\mathrm{C}-\mathrm{TiO}_{2}$ than with $\mathrm{TiO}_{2}$ (panel (B)), which suggests that partial charge transfer might occur from the carbon nanoparticles to $\mathrm{TiO}_{2}$ by $\mathrm{Ti}-\mathrm{O}-\mathrm{C}$ linkages. In addition, for $\mathrm{TiO}_{2}$, the peak at $532.1 \mathrm{eV}$ is likely due to hydroxyl $\mathrm{O}$ on the $\mathrm{TiO}_{2}$ surfaces, ${ }^{41,46}$ whereas for $\mathrm{C}-\mathrm{TiO}_{2}$, the second peak was markedly broader, spanning a large range of 528 to $538 \mathrm{eV}$ with center at $533.3 \mathrm{eV}$, which most probably included contributions from both the $\mathrm{TiO}_{2}$ hydroxyl groups as well as various oxygenated species on the carbon nanoparticle surfaces (such as carbonyl, carboxylate, phenylate, etc.). ${ }^{31,32,47}$ This again indicates that carbon nanoparticles were indeed incorporated with $\mathrm{TiO}_{2}$ to form nanoscale composites.

The intimate electronic interactions between the carbon and $\mathrm{TiO}_{2}$ nanoparticles in $\mathrm{C}-\mathrm{TiO}_{2}$ led to unique interfacial charge transfer upon photoirradiation. Fig. 3 shows the excitation (solid curves) and emission (dashed curves) fluorescence spectra of the carbon, $\mathrm{TiO}_{2}$ and $\mathrm{C}-\mathrm{TiO}_{2}$ nanoparticles. It can be seen that the carbon nanoparticles (black curves) exhibited a broad excitation spectrum centered at $c a .311 \mathrm{~nm}$ and an equally broad emission peak at approximately $428 \mathrm{~nm}$, a behavior consistent with the results reported previously that was ascribed to electronic transitions of oxygenated functional species on the nanoparticle surface. ${ }^{31,32}$ For $\mathrm{TiO}_{2}$ nanoparticles (red curves), the fluorescence features were different, where a major excitation peak might be identified at $362 \mathrm{~nm}$, along with two emission peaks at $460 \mathrm{~nm}$ and $528 \mathrm{~nm}$. Note that the excitation peak energy $(3.4 \mathrm{eV})$ is somewhat greater than the bandgap energy of bulk anatase $\mathrm{TiO}_{2}(3.2 \mathrm{eV})$, most probably as a result of lattice expansion as observed above (Fig. 1). ${ }^{35}$ It should be mentioned that reports of photoluminescence emission of $\mathrm{TiO}_{2}$ nanoparticles are generally rather few, as titania is a well-known indirect bandgap semiconductor and in most previous studies the nanoparticles possess low crystallinity and broad size distributions. ${ }^{4-52}$ In an earlier study, using a sol-gel method we prepared $\mathrm{TiO}_{2}$ nanoparticles $(5 \mathrm{~nm}$ in diameter) that were attached onto a gold Janus nanoparticle 


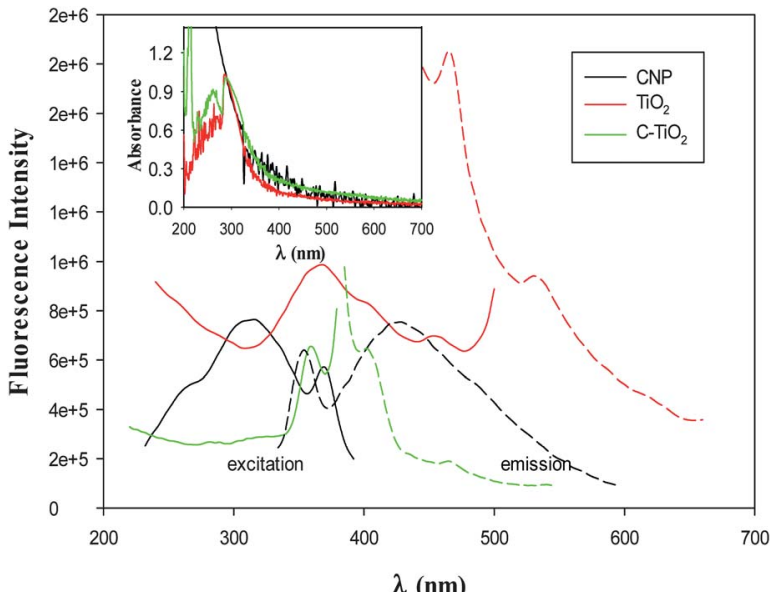

Fig. 3 Excitation (solid curves) and emission (dashed curves) fluorescence spectra of carbon, $\mathrm{TiO}_{2}$ and $\mathrm{C}-\mathrm{TiO}_{2}$ nanoparticles. The inset shows the corresponding UV-vis spectra of the three samples with the absorbance normalized to the respective value at $290 \mathrm{~nm}$.

surface and observed apparent fluorescence characteristics with the excitation and emission peaks at $c a .400$ and $609 \mathrm{~nm}$, respectively, which were ascribed to electronic transitions involving trap states of the nanoparticles. ${ }^{53}$

However, for the $\mathrm{C}-\mathrm{TiO}_{2}$ nanoparticles (green curves), the fluorescence intensity was drastically diminished in both excitation and emission measurements, with the excitation and emission peaks at $360 \mathrm{~nm}$ and $403 \mathrm{~nm}$, respectively. Note that the former is very close to that of $\mathrm{TiO}_{2}$ nanoparticles whereas the latter appears to be part of the broad emission envelope of carbon nanoparticles. This suggests that in the composite $\mathrm{C}-$ $\mathrm{TiO}_{2}$ nanoparticles, efficient charge/energy transfer likely occurred from $\mathrm{TiO}_{2}$ to carbon under photoirradiation, leading to apparent quenching of the $\mathrm{TiO}_{2}$ fluorescence. This may be facilitated by the oxygenated functional moieties on the carbon nanoparticle surface that behaved as efficient electron acceptors and were suspected to be the active sites for photoluminescence. $^{54}$

In addition, as manifested in the UV-vis absorption spectra (Fig. 3, inset), one can see that whereas $\mathrm{TiO}_{2}$ nanoparticles exhibited an absorption edge around $360 \mathrm{~nm}$ (red curve), the C$\mathrm{TiO}_{2}$ composite nanoparticles extended the absorption to the visible range (up to $450 \mathrm{~nm}$, green curve), very similar to that of the carbon nanoparticles (black curve). This again indicates that carbon nanoparticles and $\mathrm{TiO}_{2}$ nanoparticles were indeed integrated to form $\mathrm{C}-\mathrm{TiO}_{2}$ nanocomposites.

The photocatalytic activity of the $\mathrm{C}-\mathrm{TiO}_{2}$ nanocomposites was then examined by using the photodegradation of methylene blue as the illustrating example. Fig. 4 shows the UV-vis absorption spectra of methylene blue in water in the presence of $\mathrm{C}-\mathrm{TiO}_{2}$ under UV photoirradiation $(365 \mathrm{~nm})$ for various periods of time. It can be clearly seen that within the range of 500 to $800 \mathrm{~nm}$, two major absorption peaks appear at about 612 and $664 \mathrm{~nm}$ which were characteristic of methylene blue, ${ }^{55}$ and when exposed to UV light the absorbance diminished apparently with increasing exposure time, indicating effective

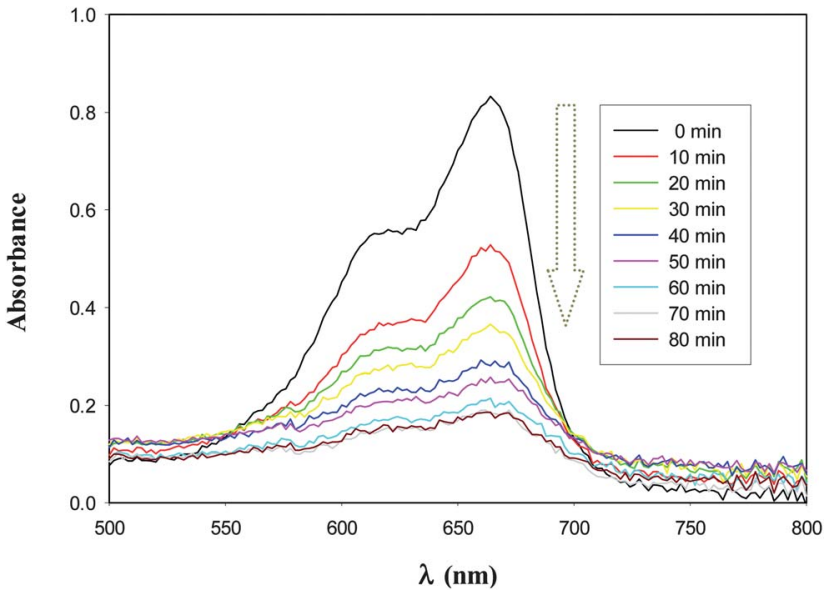

Fig. 4 UV-vis absorption spectra of methylene blue (MB) in water as a function of reaction times catalyzed by $\mathrm{C}-\mathrm{TiO}_{2}$ nanoparticles. The concentrations of the $\mathrm{C}-$ $\mathrm{TiO}_{2}$ nanoparticles and $\mathrm{MB}$ were $0.5 \mathrm{mg} \mathrm{mL}^{-1}$ and $20 \mathrm{mg} \mathrm{L}^{-1}$ respectively.

photocatalytic activity of the $\mathrm{C}-\mathrm{TiO}_{2}$ nanocomposites in the degradation of methylene blue. From the optical absorbance at $664 \mathrm{~nm}\left(A_{664}\right)$, the fraction of methylene blue that was degraded could be estimated, $\left(A_{\mathrm{o}, 664}-A_{664}\right) / A_{\mathrm{o}, 664}$, where $A_{\mathrm{o}, 664}$ denotes the absorbance prior to UV light irradiation (i.e., $t=0 \mathrm{~min}$ ). The corresponding reaction dynamics is depicted in Fig. 5 (yellow diamonds). The photocatalytic activities of the carbon, $\mathrm{TiO}_{2}$ nanoparticles and their simple mixture were also evaluated in a similar fashion and included for comparison.

It can be seen that for carbon nanoparticles alone (black circles), there was virtually no change of the optical absorption even after four hours of UV photoirradiation of the methylene blue solution, indicating little photocatalytic activity. For $\mathrm{TiO}_{2}$ nanoparticles (red triangles), the fraction of methylene blue that was photodegraded increased almost linearly with reaction time, and after 120 min of UV light irradiation, about $70 \%$ of

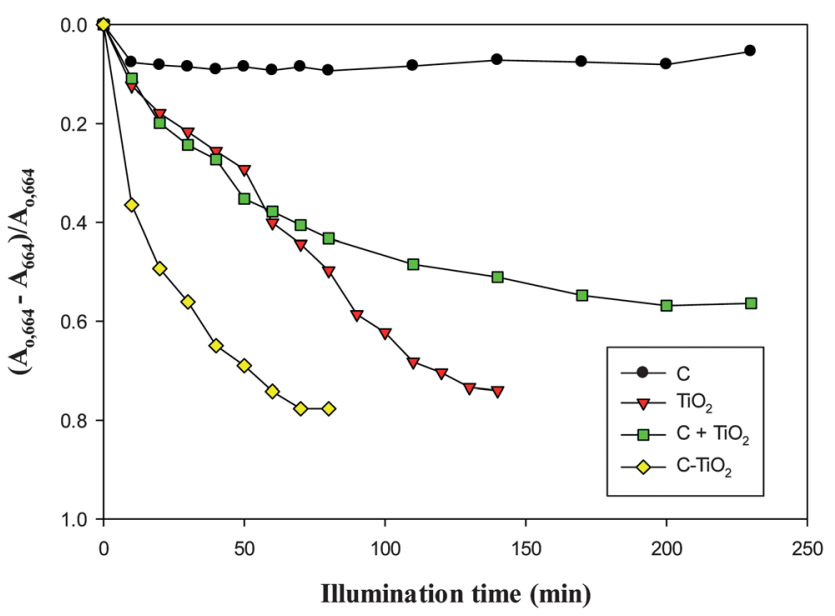

Fig. 5 Photodegradation efficiency of carbon, $\mathrm{TiO}_{2}$, and $\mathrm{C}-\mathrm{TiO}_{2}$ nanoparticles, as well as the simple mixture of carbon nanoparticles and $\mathrm{TiO}_{2}$ nanoparticles $(\mathrm{C}+$ $\mathrm{TiO}_{2}$ ) under UV light irradiation. Data were acquired from UV-vis absorption measurements as exemplified in Fig. 4. 
methylene blue was consumed. Note that when carbon and $\mathrm{TiO}_{2}$ nanoparticles were simply mixed together (with a quantity and mass ratio similar to those of $\mathrm{C}-\mathrm{TiO}_{2}$ ) into the reaction solution (green squares), the reactivity in the early stage of the reactions ( $\sim 60 \mathrm{~min}$ ) was almost identical to that of $\mathrm{TiO}_{2}$ nanoparticles, suggesting that the $\mathrm{TiO}_{2}$ nanoparticles were the major contributors in the mixture to the photocatalytic activity; at longer reaction times (>60 min), the activity of the carbon and $\mathrm{TiO}_{2}$ nanoparticle mixtures actually diminished. In sharp contrast, the activity of the $\mathrm{C}-\mathrm{TiO}_{2}$ nanocomposites (yellow diamonds) was markedly better. After only $60 \mathrm{~min}$ of UV light photoirradiation, more than $75 \%$ of methylene blue was degraded already. That is, within the present experimental context, the photocatalytic activity of $\mathrm{C}-\mathrm{TiO}_{2}$ nanocomposites was about twice that of $\mathrm{TiO}_{2}$ alone, and the performance increased in the order of carbon nanoparticles $<$ mixture of carbon and $\mathrm{TiO}_{2}$ nanoparticles $\leq \mathrm{TiO}_{2}$ nanoparticles $<\mathrm{C}-\mathrm{TiO}_{2}$ nanocomposites. This indicates that intimate contacts and hence electronic interactions between the carbon and $\mathrm{TiO}_{2}$ nanoparticles in the $\mathrm{C}-\mathrm{TiO}_{2}$ nanocomposites were likely to be the key factors that facilitated interfacial charge separation upon photoirradiation and hence led to improved photocatalytic activity, consistent with the effective diminishment of the photoluminescence emission of $\mathrm{C}-\mathrm{TiO}_{2}$ as compared to that of $\mathrm{TiO}_{2}$ nanoparticles alone (Fig. 3).

As mentioned earlier, the carbon nanoparticle surface was decorated with various oxygenated functional moieties, including quinone derivatives, such as 9,10-phenanthraquinone, that are well-known electron acceptors. ${ }^{31,32,56}$ For instance, previously we observed that the carbon nanoparticles exhibited two pairs of voltammetric peaks with the formal potentials at $-0.28 \mathrm{~V}$ and $-0.06 \mathrm{~V}(v s$. $\mathrm{Ag} / \mathrm{AgCl})$ in electrochemical measurements. ${ }^{54}$ Note that in neutral solutions, the conduction band of $\mathrm{TiO}_{2}$ is located at $c a .-0.35 \mathrm{~V}(v s . \mathrm{Ag} / \mathrm{AgCl})$ whereas the valence band is at $c a .+2.65 \mathrm{~V}^{57}$ Thus, under UV photoirradiation, the valence electrons of $\mathrm{TiO}_{2}$ were excited to the conduction band, which then crossed the carbon- $\mathrm{TiO}_{2}$ interface and were accepted by the quinone moieties of the carbon nanoparticles. Such photogenerated electrons were then used to reductively degrade methylene blue, hence leading to the diminishment of the optical absorption (the corresponding holes were likely involved in the oxidation of water). For the physical mixture of carbon and $\mathrm{TiO}_{2}$ nanoparticles, the lack of bonding interactions greatly impeded charge/energy transfer between them and thus they behaved independently, as observed above.

It should be noted that in earlier studies of carbon-supported $\mathrm{TiO}_{2}$, the enhanced photocatalytic activities were largely attributed to the enhanced dispersion and/or crystallinity (by thermal treatments) of $\mathrm{TiO}_{2}$, whereas the impacts of the chemical reactivity of the carbon support were largely ignored. ${ }^{21-27}$ In the present study, using equally nanosized $\mathrm{TiO}_{2}$ particles as the comparative example, one can see that the rich surface chemistry of carbon nanoparticles might also be exploited to facilitate charge separation upon UV photoirradiation, leading to further enhancement of the photocatalytic performance.

\section{Conclusions}

A functional C- $\mathrm{TiO}_{2}$ nanocomposite was prepared by the growth of $\mathrm{TiO}_{2}$ on carbon nanoparticles by a simple hydrothermal procedure. XPS measurements showed that partial charge transfer occurred from carbon nanoparticles to the Ti(Iv) centers in the oxide nanoparticles by the $\mathrm{Ti}-\mathrm{O}-\mathrm{C}$ interfacial bonds, in comparison to pure $\mathrm{TiO}_{2}$ nanoparticles. Because of these intimate electronic interactions, the $\mathrm{C}-\mathrm{TiO}_{2}$ nanoparticles exhibited apparent diminishment of the photoluminescence as compared to $\mathrm{TiO}_{2}$ and carbon nanoparticles, suggesting that effective electron/energy transfer occurred in the nanocomposites under photoirradiation. Such unique properties were exploited for the enhancement of the photocatalytic activity of $\mathrm{C}-\mathrm{TiO}_{2}$ nanocomposites, as illustrated in the photodegradation of methylene blue, which was ascribed to the improved efficiency of interfacial charge separation from $\mathrm{TiO}_{2}$ to carbon because of abundant electron-accepting sites on the carbon nanoparticles.

\section{Acknowledgements}

This work was supported, in part, by the National Science Foundation (CHE - 1012258, CBET - 1258839 and DMR 0804049) and the ACS Petroleum Research Fund (49137 ND10). C. L. acknowledged partial support of a research fellowship from the China Scholarship Council. XPS and TEM studies were carried out at the Molecular Foundry and National Center for Electron Microscopy, Lawrence Berkeley National Laboratory, as part of a user project.

\section{Notes and references}

1 K. Hashimoto, H. Irie and A. Fujishima, Jpn. J. Appl. Phys., 2005, 44, 8269-8285.

2 J. Zhu, J. Yang, Z.-F. Bian, J. Ren, Y.-M. Liu, Y. Cao, H.-X. Li, H.-Y. He and K.-N. Fan, Appl. Catal., B, 2007, 76, 82-91.

3 P. P. Das, S. K. Mohapatra and M. Misra, J. Phys. D: Appl. Phys., 2008, 41, 245103.

4 A. Benoit, I. Paramasivam, Y. C. Nah, P. Roy and P. Schmuki, Electrochem. Commun., 2009, 11, 728-732.

5 Z.-X. Li, Y.-L. Xie, H. Xu, Y.-M. Wang, Z.-G. Xu and H.-L. Zhang, J. Photochem. Photobiol., A, 2011, 224, 25-30.

6 H.-i. Kim, J. Kim, W. Kim and W. Choi, J. Phys. Chem. C, 2011, 115, 9797-9805.

7 H. Y. Yang, S. F. Yu, S. P. Lau, X. Zhang, D. D. Sun and G. Jun, Small, 2009, 5, 2260-2264.

8 X. Chen, Y. Su, X. Zhang and L. Lei, Chin. Sci. Bull., 2008, 53, 1983-1987.

9 L. Deng, S. Wang, D. Liu, B. Zhu, W. Huang, S. Wu and S. Zhang, Catal. Lett., 2009, 129, 513-518.

10 P. Xu, T. Xu, J. Lu, S. Gao, N. S. Hosmane, B. Huang, Y. Dai and Y. Wang, Energy Environ. Sci., 2010, 3, 1128.

11 H. Zhao, Y. Chen, X. Quan and X. Ruan, Chin. Sci. Bull., 2007, 52, 1456-1461.

12 K. E. deKrafft, C. Wang and W. B. Lin, Adv. Mater., 2012, 24, 2014-2018. 
13 J. Wang and Z. Lin, Chem. Mater., 2010, 22, 579-584.

14 Y. Park, S.-H. Lee, S. O. Kang and W. Choi, Chem. Commun., 2010, 46, 2477.

15 T. T. Le, M. S. Akhtar, D. M. Park, J. C. Lee and O. B. Yang, Appl. Catal., B, 2012, 111-112, 397-401.

16 C. Dong, A. Xian, E. H. Han and J. Shang, Solid State Phenom., 2007, 121, 939-942.

17 D. Chu, X. Yuan, G. Qin, M. Xu, P. Zheng, J. Lu and L. Zha, J. Nanopart. Res., 2007, 10, 357-363.

18 Y. Park, W. Kim, H. Park, T. Tachikawa, T. Majima and W. Choi, Appl. Catal., B, 2009, 91, 355-361.

19 X. Wang, S. Meng, X. Zhang, H. Wang, W. Zhong and Q. Du, Chem. Phys. Lett., 2007, 444, 292-296.

20 Z. Wu, F. Dong, W. Zhao, H. Wang, Y. Liu and B. Guan, Nanotechnology, 2009, 20, 235701.

21 S. Mozia, M. Toyoda, T. Tsumura, M. Inagaki and A. W. Morawski, Desalination, 2007, 212, 141-151.

22 S. Shanmugam and A. Gedanken, Small, 2007, 3, 1189-1193.

23 B. Tryba, A. W. Morawski, T. Tsumura, M. Toyoda and M. Inagaki, J. Photochem. Photobiol., A, 2004, 167, 127-135.

24 T. Tsumura, N. Kojitani, I. Izumi, N. Iwashita, M. Toyoda and M. Inagaki, J. Mater. Chem., 2002, 12, 1391-1396.

25 B. Tryba, A. W. Morawski and M. Inagaki, Appl. Catal., B, 2003, 46, 203-208.

26 B. Tryba, A. W. Morawski and M. Inagaki, Appl. Catal., B, 2003, 41, 427-433.

27 D. Xu, Z.-H. Huang, F. Kang, M. Inagaki and T. H. Ko, Catal. Today, 2008, 139, 64-68.

28 Y. Li, D.-S. Hwang, N. H. Lee and S.-J. Kim, Chem. Phys. Lett., 2005, 404, 25-29.

29 G. Wu, T. Nishikawa, B. Ohtani and A. Chen, Chem. Mater., 2007, 19, 4530-4537.

30 B. Tryba, A. W. Morawski, T. Tsumura, M. Toyoda and M. Inagaki, J. Photochem. Photobiol., A, 2004, 167, 127-135.

31 Y. Song, X. Kang, N. B. Zuckerman, B. Phebus, J. P. Konopelski and S. Chen, Nanoscale, 2011, 3, 1984.

32 L. Tian, D. Ghosh, W. Chen, S. Pradhan, X. Chang and S. Chen, Chem. Mater., 2009, 21, 2803-2809.

33 D. Pan, N. Zhao, Q. Wang, S. Jiang, X. Ji and L. An, Adv. Mater., 2005, 17, 1991-1995.

34 L. Wang, L. Zang, J. C. Zhao and C. Y. Wang, Chem. Commun., 2012, 48, 11736-11738.

35 G. S. Li, J. Boerio-Goates, B. F. Woodfield and L. P. Li, Appl. Phys. Lett., 2004, 85, 2059-2061.

36 G. An, W. Ma, Z. Sun, Z. Liu, B. Han, S. Miao, Z. Miao and K. Ding, Carbon, 2007, 45, 1795-1801.
37 D. Song, J. Hrbek and R. Osgood, Nano Lett., 2005, 5, 13271332.

38 Y. H. Zhang, P. Xiao, X. Y. Zhou, D. W. Liu, B. B. Garcia and G. Z. Cao, J. Mater. Chem., 2009, 19, 948-953.

39 L. Zhao, X. Chen, X. Wang, Y. Zhang, W. Wei, Y. Sun, M. Antonietti and M.-M. Titirici, Adv. Mater., 2010, 22, 3317-3321.

40 S. T. Kochuveedu, Y. J. Jang, Y. H. Jang, W. J. Lee, M. A. Cha, H. Shin, S. Yoon, S. S. Lee, S. O. Kim, K. Shin, M. Steinhart and D. H. Kim, Green Chem., 2011, 13, 3397-3405.

41 X.-K. Wang, C. Wang and D. Zhang, Mater. Lett., 2012, 72, 12-14.

42 R. Hang, X. Huang, L. Tian, Z. He and B. Tang, Electrochim. Acta, 2012, 70, 382-393.

43 J. Fang, X. Bi, D. Si, Z. Jiang and W. Huang, Appl. Surf. Sci., 2007, 253, 8952-8961.

44 P. Stefanov, M. Shipochka, P. Stefchev, Z. Raicheva, V. Lazarova and L. Spassov, J. Phys.: Conf. Ser., 2008, 100, 012039.

45 C. Rath, P. Mohanty, A. C. Pandey and N. C. Mishra, J. Phys. D: Appl. Phys., 2009, 42, 205101.

46 B. Adolphi, E. Jähne, G. Busch and X. Cai, Anal. Bioanal. Chem., 2004, 379, 646-652.

47 C. D. Wagner and G. E. Muilenberg, Handbook of X-ray photoelectron spectroscopy: a reference book of standard data for use in X-ray photoelectron spectroscopy, Perkin-Elmer Corp., Physical Electronics Division, Eden Prairie, Minn, 1979.

48 M. Niederberger, M. H. Bartl and G. D. Stucky, Chem. Mater., 2002, 14, 4364-4370.

49 G. Ramakrishna and H. N. Ghosh, Langmuir, 2003, 19, 505508.

50 Y. C. Zhu and C. X. Ding, J. Solid State Chem., 1999, 145, 711-715.

51 H. Tang, K. Prasad, R. Sanjines, P. E. Schmid and F. Levy, J. Appl. Phys., 1994, 75, 2042-2047.

52 J. I. Pankove, Optical processes in semiconductors, PrenticeHall, Englewood Cliffs, NJ, 1971.

53 S. Pradhan, D. Ghosh and S. W. Chen, ACS Appl. Mater. Interfaces, 2009, 1, 2060-2065.

54 L. Tian, Y. Song, X. Chang and S. Chen, Scr. Mater., 2010, 62, 883-886.

55 X. W. Kang and S. W. Chen, J. Mater. Sci., 2010, 45, 26962702.

56 J. E. Gautrot, P. Hodge, M. Helliwell, J. Raftery and D. Cupertino, J. Mater. Chem., 2009, 19, 4148-4156.

57 A. J. Nozik and R. Memming, J. Phys. Chem., 1996, 100, 13061-13078. 